\title{
Integrative genomic analyses of the RNA-binding protein, RNPC1, and its potential role in cancer prediction
}

\author{
ZHIMING DING $^{1^{*}}$, HAI-WEI YANG ${ }^{2 *}$, TIAN-SONG XIA ${ }^{3 *}$, BO WANG $^{4}$ and QIANG DING ${ }^{3}$ \\ ${ }^{1}$ Department of Neurosurgery, The Eastern Hospital of the First Affiliated Hospital, Sun Yat-sen University, \\ Guangzhou, Guangdong 510700; Departments of ${ }^{2}$ Urology and ${ }^{3}$ Breast Surgery, The First Affiliated Hospital of \\ Nanjing Medical University, Nanjing, Jiangsu 210029; ${ }^{4}$ Department of Medical Oncology, The Eastern Hospital \\ of the First Affiliated Hospital, Sun Yat-sen University, Guangzhou, Guangdong 510700, P.R. China
}

Received February 6, 2015; Accepted May 26, 2015

DOI: $10.3892 /$ ijmm.2015.2237

\begin{abstract}
The RNA binding motif protein 38 (RBM38, also known as RNPC1) plays a pivotal role in regulating a wide range of biological processes, from cell proliferation and cell cycle arrest to cell myogenic differentiation. It was originally recognized as an oncogene, and was frequently found to be amplified in prostate, ovarian and colorectal cancer, chronic lymphocytic leukemia, colon carcinoma, esophageal cancer, dog lymphomas and breast cancer. In the present study, the complete RNPC1 gene was identified in a number of vertebrate genomes, suggesting that RNPC1 exists in all types of vertebrates, including fish, amphibians, birds and mammals. In the different genomes, the gene had a similar 4 exon/3 intron organization, and all the genetic loci were syntenically conserved. The phylogenetic tree demonstrated that the RNPC1 gene from the mammalian, bird, reptile and teleost lineage formed a species-specific cluster. A total of 34 functionally relevant single nucleotide polymorphisms (SNPs), including 14 SNPs causing missense mutations, 8 exonic splicing enhancer SNPs and 12 SNPs causing nonsense mutations, were identified in the human RNPC1 gene. RNPC1 was found to be expressed in bladder, blood, brain, breast, colorectal, eye, head and neck, lung, ovarian, skin and soft tissue cancer. In 14 of the 94 tests, an association between RNPC1
\end{abstract}

Correspondence to: Dr Zhiming Ding, Department of Neurosurgery, The Eastern Hospital of the First Affiliated Hospital, Sun Yat-sen University, 183 Huangpu East Road, Guangzhou, Guangdong 510700, P.R. China

E-mail: dzming930@sohu.com

Dr Qiang Ding, Department of Breast Surgery, The First Affiliated Hospital of Nanjing Medical University, 300 Guangzhou Road, Nanjing, Jiangsu 210029, P.R. China

E-mail: dingqiang@njmu.edu.cn

*Contributed equally

Key words: RNPC1, comparative genomics, cancer, prognosis, meta-analysis gene expression and cancer prognosis was observed. We found that the association between the expression of RNPC1 and prognosis varied in different types of cancer, and even in the same type of cancer from the different databases used. This suggests that the function of RNPC1 in these tumors may be multidimensional. The sex determining region Y (SRY)-box 5 (Sox5), runt-related transcription factor 3 (RUNX3), CCAAT displacement protein 1 (CUTL1), v-rel avian reticuloendotheliosis viral oncogene homolog (Rel)A, peroxisome proliferator-activated receptor $\gamma$ isoform 2 (PPAR $\gamma 2$ ) and activating transcription factor 6 (ATF6) regulatory transcription factor binding sites were identified in the upstream (promoter) region of the RNPC1 gene, and may thus be involved in the effects of RNPC1 in tumors.

\section{Introduction}

RNA-binding proteins (RBPs) are known to play a crucial role in post-transcriptional regulation in gene expression, and regulate all aspects of RNA metabolism and function, such as polyadenylation, RNA splicing, transport, stability and translation; thus, they represent critical mechanisms for gene regulation in mammalian cells $(1,2)$. They contain one or more RNA-binding motifs, such as the RNA recognition motif (RRM), the human heterogeneous nuclear ribonucleoprotein (hnRNP) K homology motif, the RGG box and the double-stranded RNA binding domain (dsRBD) motif. RRM is the most prevalent type of eukaryotic RNA-binding motif (3), which is composed of two submotifs, RNP1 and RNP2 (3). RBPs are involved in the expression of various genes responsible for regulating biological processes and cellular functions, and thus expected mutations or the aberrant production of RBPs can cause cancer progression $(4,5)$.

The RNA binding motif protein 38 (RBM38, also known as RNPC1) gene is located on chromosome $20 \mathrm{q} 13$ and is expressed in a variety of tissues. It belongs to the RRM family of RBPs, is expressed as RNPC1a with 239 amino acids and as RNPC1b with 121 amino acids (6). RNPC1 plays pivotal roles in regulating a wide range of biological processes, ranging from cell proliferation and cell cycle arrest to cell myogenic differentiation $(7,8)$. It is capable of regulating these biological processes by binding and stabilizing the mRNA of p21, p73, 
Hu antigen $\mathrm{R}(\mathrm{HuR})$ and macrophage inhibitory cytokine-1 (MIC-1) $(6,7,9,10)$, or by binding to the mRNAs of $\mathrm{p} 63$, murine double minute-2 (MDM2) and p53 and mediating the decrease in the mRNA levels and the attenuation of the translation of these proteins (11-13).

RNPC1 was originally recognized as an oncogene, and was frequently found to be amplified in prostate $(14,15)$, ovarian cancer (16), colorectal cancer $(17,18)$, chronic lymphocytic leukemia (19), colon carcinoma (20), esophageal adenocarcinoma (21), dog lymphomas (13) and breast cancer (22-24). Recently, new evidence suggests that RNPC1 acts as a tumor suppressor. It has been reported that RNPC1 is part of a negative feedback loop, which restricts E2F transcription factor 1 (E2F1) activity by limiting cell cycle progression at the G1-S boundary (25). The expression of RNPC1 has been shown to highly correlate with increased survival in patients with ovarian cancer (25). In breast cancer, RNPC1 functions as a tumor repressor, possibly through promoter hypermethylation silencing (26). In the present study, we identified RNPC1 genes from mammalian genomes using comparative genomic analyses. We then searched for conserved transcription factorbinding sites within the promoter regions of the human RNPC1 gene. Analysis of the expression data and functionally relevant single nucleotide polymorphisms (SNPs), and comparative proteomic analyses were conducted. Furthermore, a metaanalysis of the prognostic value of the RNPC1 gene in various types of cancer was also performed.

\section{Materials and methods}

Identification of the complete RNPC1 gene in vertebrate genomes and integrative genomic analyses. The RNPC1 gene and amino acid sequences were selected from the Ensembl database (http://www.ensembl.org/index.html), based on orthologous and paralogous associations. The selected RNPC1 sequences were applied as queries in order to search for the RNPC1 gene using the BLAST tool at the National Center for Biotechnology Information (NCBI), in order to confirm whether their best hit was an RNPC1 gene (27-33). The number, length and structure of the exons and introns in the RNPC1 gene in all species were collected from Ensembl. The number and length of the RNPC1 exons and introns in all sequences were then subjected to exon-intron conservation analyses. Conserved transcription factor-binding sites within the promoter region of the human RNPC1 gene were obtained from the SABiosciences' proprietary database, which combines Text Mining Application and data from the UCSC Genome Browser (http://genome.ucsc.edu/) (27-33).

Comparative proteomic analyses of RNPC1 protein. The protein-coding sequences of RNPC1 were aligned using the ClustalW program in MEGA 5.05. We constructed a maximum likelihood (ML) tree of RNPC1 amino acid sequences using MEGA 5.05 with the optimal model (Kimura 2-parameter). Relative support of the internal node was performed by bootstrap analyses with 1,000 replications for ML reconstructions (34). The CodeML program, implemented in the PAML 4.7 software package, was used to investigate whether the RNPC1 protein is under positive selection (35). The site-specific model was developed using the likelihood ratio test (LRT) to compare the M7 (null model) with the M8 model. M7 is a null model that does not allow for any codons with $\omega>1$, whereas the M8 model allows for positively selected sites $(\omega>1)$. When the M8 model fits the data significantly (P-value $<0.05$ ) better than the null model (M7), the presence of sites with $\omega>1$ is suggested. On the contrary, the results of $\mathrm{P}$-value $>0.05$ are proof the absence of sites with $\omega>1$. Twice the log likelihood difference between the two compared models $(2 \Delta \mathrm{l})$ is compared against $\chi^{2}$ with critical values being 5.99 and 9.21 at the 0.05 and 0.01 significance levels, respectively (36).

Identification of functionally relevant SNPs in the human RNPC1 gene and somatic mutations in human cancer. Functionally relevant SNPs of the human RNPC1 gene were identified as previously described (27-33). The SNPs were extracted from Ensembl (http://www.ensembl.org) and NCBI's SNPdb (http://www.ncbi.nlm.nih.gov). The SNPs that disrupted exonic splicing enhancer (ESE)/exonic splicing silencer (ESS) motifs and caused missence mutations were also identified. The identification of somatic mutations of the human RNPC1 gene in human cancer was conducted using COSMIC, a database for mining complete cancer genomes in the catalogue of somatic mutations in cancer (37).

Analysis of the expression of the human RNPCl gene. The expression profiles of RNPC1 in normal human tissues were obtained from ArrayExpress (38). Virtual northern blot analysis of NCBI's UniGene dataset was also performed, as previously described (31-33).

Meta-analysis of the prognostic value of the RNPC1 gene in cancer. For meta-analysis, the PrognoScan database was used (39). This includes: i) a large collection of publicly available cancer microarray datasets with clinical annotation, and ii) a tool for assessing the biological association between gene expression and prognosis. PrognoScan employs the minimum P-value approach to group patients for survival analysis. PrognoScan provides a powerful platform for evaluating potential tumor markers and therapeutic targets, and is publicly accessible at http://www.prognoscan.org/. The human RNPC1 gene was inputted as a query, and the data were collected for analysis. PrognoScan displays a summary in table format of tests for RNPC1 with columns for dataset, cancer type, subtype, endpoint, cohort, contributor, array type, probe ID, number of patients, optimal cutpoint, Pmin and Pcor.

\section{Results}

Comparative proteomic analysis of the RNPC1 protein identified in vertebrate genomes. All the RNPC1 nucleotide and protein sequences were collected from ENSEMBL and checked using BLAST at NCBI. The complete RNPC1 gene was identified in the human, bushbaby, chimpanzee, macaque, gorilla, olive baboon, vervet-AGM (vervet monkey), guinea pig, mouse, rat, cow, dog, ferret, hedgehog, armadillo, elephant, lesser hedgehog tenrec, anole lizard, chicken, Chinese softshell turtle, duck, Amazon molly, flycatcher, cave fish, Fugu, medaka, platyfish, spotted gar, stickleback, tilapia, Tetraodon and zebrafish genomes. The sequences and structural alignment of RNPC1 in these genomes are shown in Fig. 1. The phylogenetic tree 
A

chitroanzee

Gorilla

Hacaque

Olive_boboen

Ozangutan

Vervet-daM

Guines_Pig

Youse

Rat

Eat

Tor

Dog

Eerret

Hedgehog

Hozse

yicrobat

Pag

Amtad:110

Elephant

Legsez_hedqehog_tenzec

anole_dizazd

Chicken

Chinese_go:tahe11_turtle

Duck

Elycatche:

Zebra_Finch

Avazon_molly-:

Avesos mol1y-2

Cave_tish-1

Eave_tish-2

Fugu

Extน

yecaka

Placy?ish

Placy:ish

Spoteed_ga:

Stickieback

Ietzaodon

Iilapia-1

I:lapie-2

Zebraisish

congengug

Huran

Bughbaby

chimpanzee

Gorilia

Macague

O11ve_baboon

D:angutan

Vervet-AGM

Suinea_Pig

Moure

Rat

Tat

cor

Dog

Hedgehog

Hozse

Yacrobat

Piq

Aтread:110

Elephant

Legye:_hedgehog_tenzec

Anole inzazd

Chicken

Chinese_sortghell_turtie

Dack

Elyeatche:

Zebra Finch

Arazon molly-1

inazon-molly-2

Cave_tish-1

cave_tioh-:

กิดน

זษุ

Mecaka

Platy?ish

Piatylah

Spotted_gaz

Strekieback

Ietraodon

I:lapia-1

Tाlania-2

Zebra?igh

Eongensus

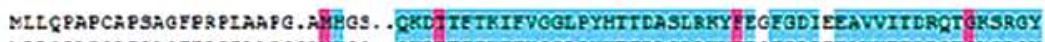
MLLGPAPCAFSAGFFRFEAAFGGAMBGS. . QRDTIETKIFVGGLPYHTTDASLRKYFEGFGDIEEAVVITDRQTGRSRGY MLLCPAFCAFSAGFFRFLAAFG. AMEGS. . CRDIIIETRIFVGGLPYHITCASLRRYIEGEGDIEEAVVITDRQTGRSRGY

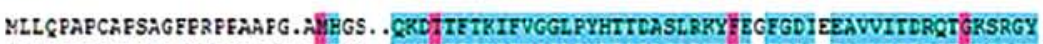

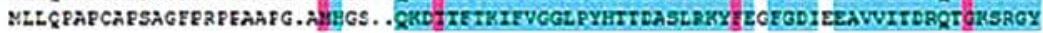

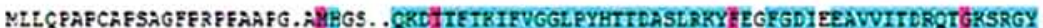

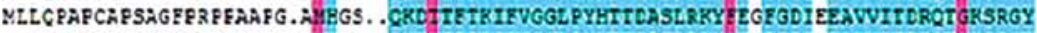
MLLCPACSFSVEFRFSAAFS. AYEGS. . QRDTIETRIFVGGLPYHTTCASLRRYIEGEGDIEEAVVITDRQTGRSRGY

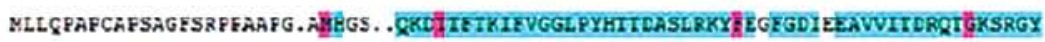

M̈BGS. . CRDITETRIFVGGL PYHTTDASLRKYFEGEGDIREAVVITDRQTGRSRGY

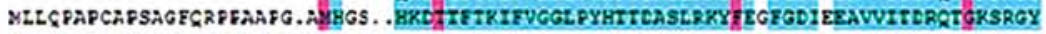

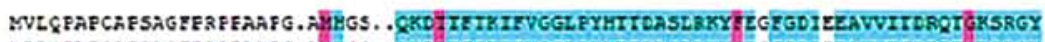

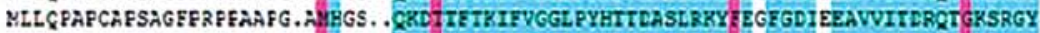
MEGS. . CRDIIETKIFVGGL PYHTTDASLRKYREGEGDIEEAVVITDRHTGKSRGY

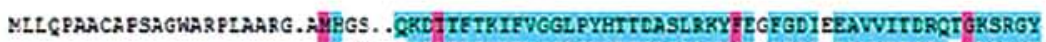
MEPV.. PKDIIETKIFVOOLPYHTLASLRKYIEOZODIEEAWVITDRQSOKSROY

MATV. . CRDITETKIFVGGRPYHITU SSLRKYIEGFGDIEEAVVITDRPTGKSRGY MBTT. . CKDTIFTKIFVGGLPYHTTLSSL RKYTEVFGDIEEAVVITDRQTGKSRGY METV. . CKDIIETKIFVGGLPYHITLSSLRKYEEVEGDIEEAVVITDRTTGKSRGY

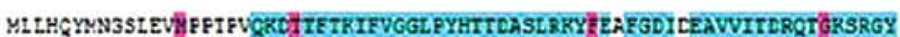

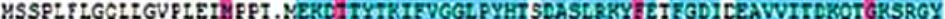
MLVHCSVS. . AFEHRAV, GRIDTIETKIFVGGL PYHATDASL BEYFGSEGEISEAVVITDROTGRSRGY

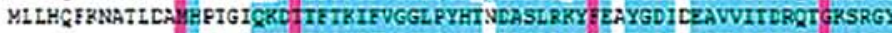

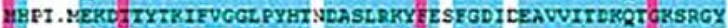

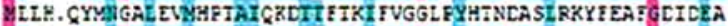

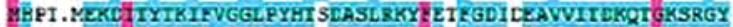
MLLHCYMNGSIEVMFETFVQR. ITTI KIFVGGLFYHTTLASLRKYIEM GDIDEAVVITCRQTGKSRGYGFV

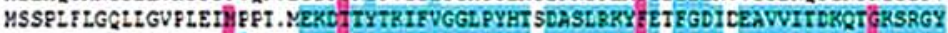

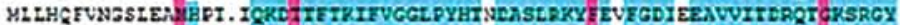
MEFT.NERDTIHTRIFVGGLPYHTNDASLRRYIETFGDICEAVVITDRQTGKSRGY MBPTAECKDIIETKIFVGGLPYHTNDASLRKYFEAYGDICEAVVITDRRTGKSRGY MSSPLFLGGIVGVPLETMBFT.NEKDITYTRIFVGGL PYHT NDASLRKYFETEGDICEAVVITDKQTGKSRGY MILHCYNSAICVMBPTAICKDTIETRIFVGGL PYHTNDASLRRY EAFGDICEAVVITDRQTERSRGY MLL.HGFVNGTLETEYFS. ICRDTTETRIFVGGL PYHTTCASLRBXEETFGDICEAVUTTDROTGRSRGX

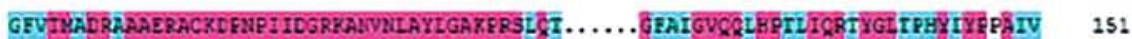

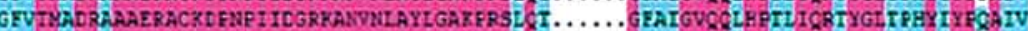

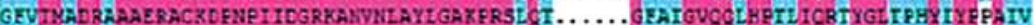

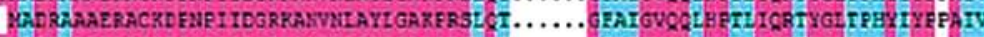

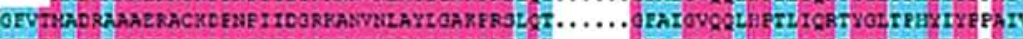

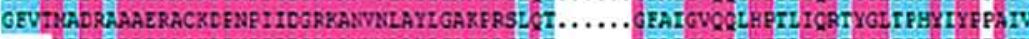

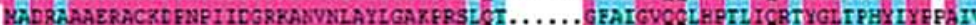

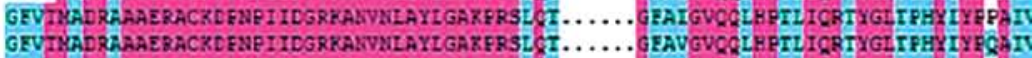

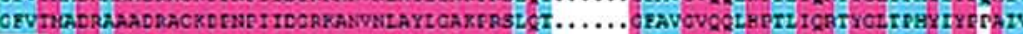

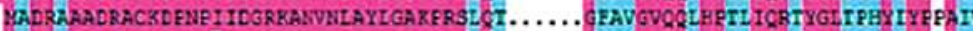

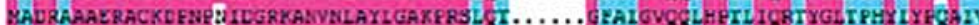

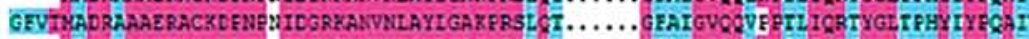

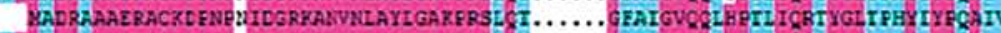

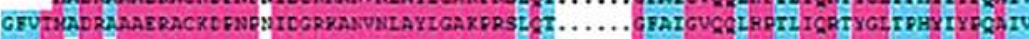

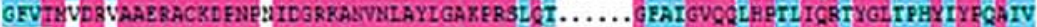

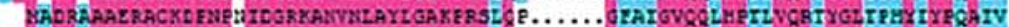

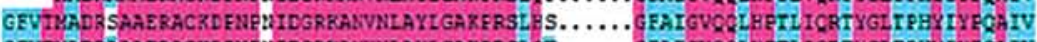

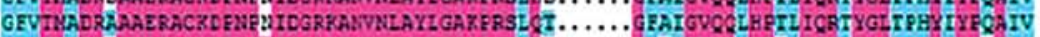

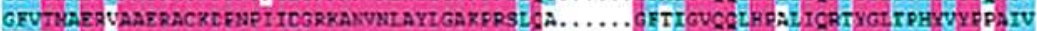

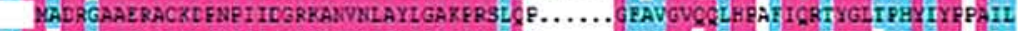

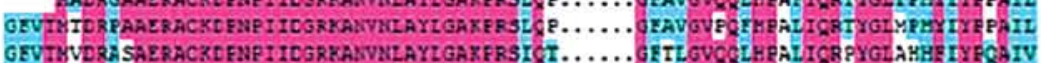

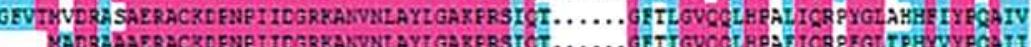

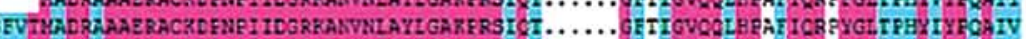

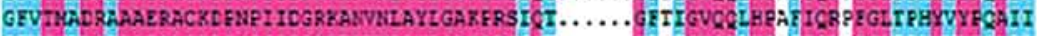

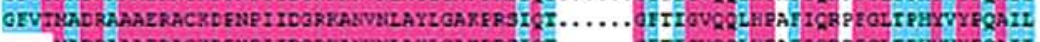

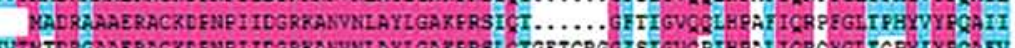

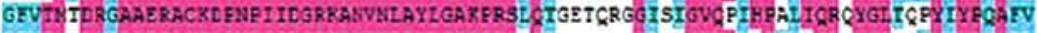

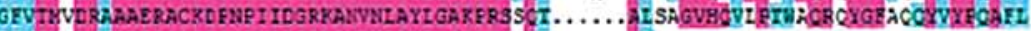
GEVTMIERAAAERACKDENPIIDGRKALYMLAYLGARERSECT......GI

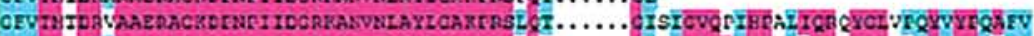

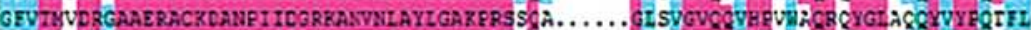

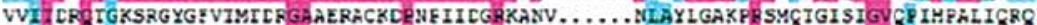

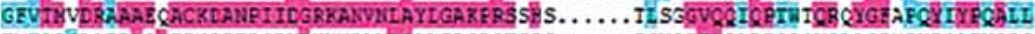

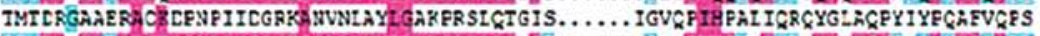

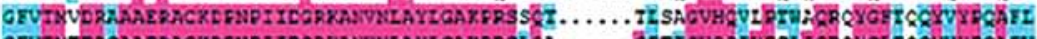

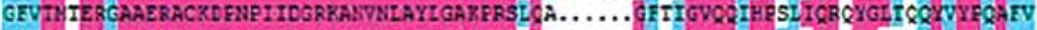

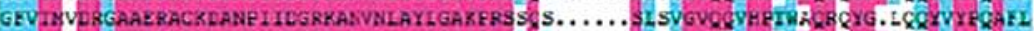

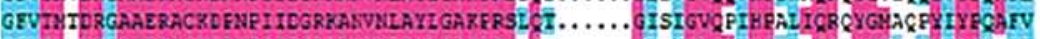

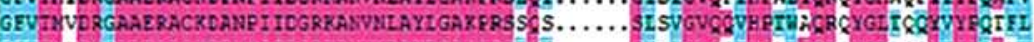

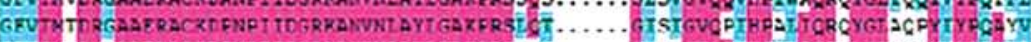

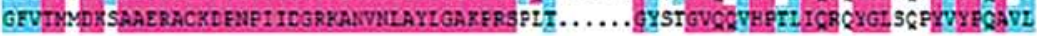

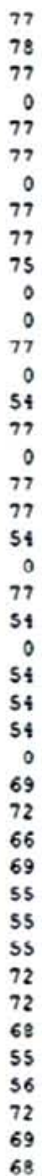

152

15:

70

$15:$

70

151

$15:$
110

70

70

151

70
128

151

70

151

128

70

152

128
70

10

128

128

70

146
$11:$

213

129

129

129

146

146

130

146

Figure 1. Sequence and structural alignment of RNPC1 in vertebrates. (A) Alignment of RNPC1 in vertebrates from position 1-151. 


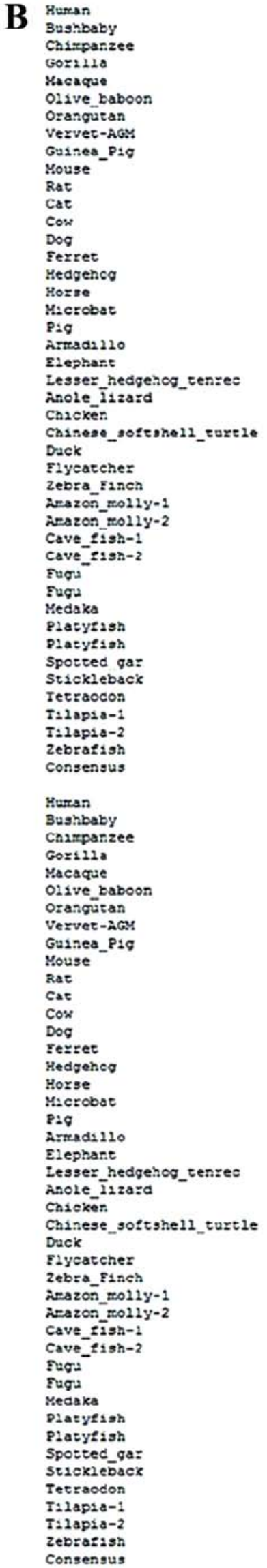

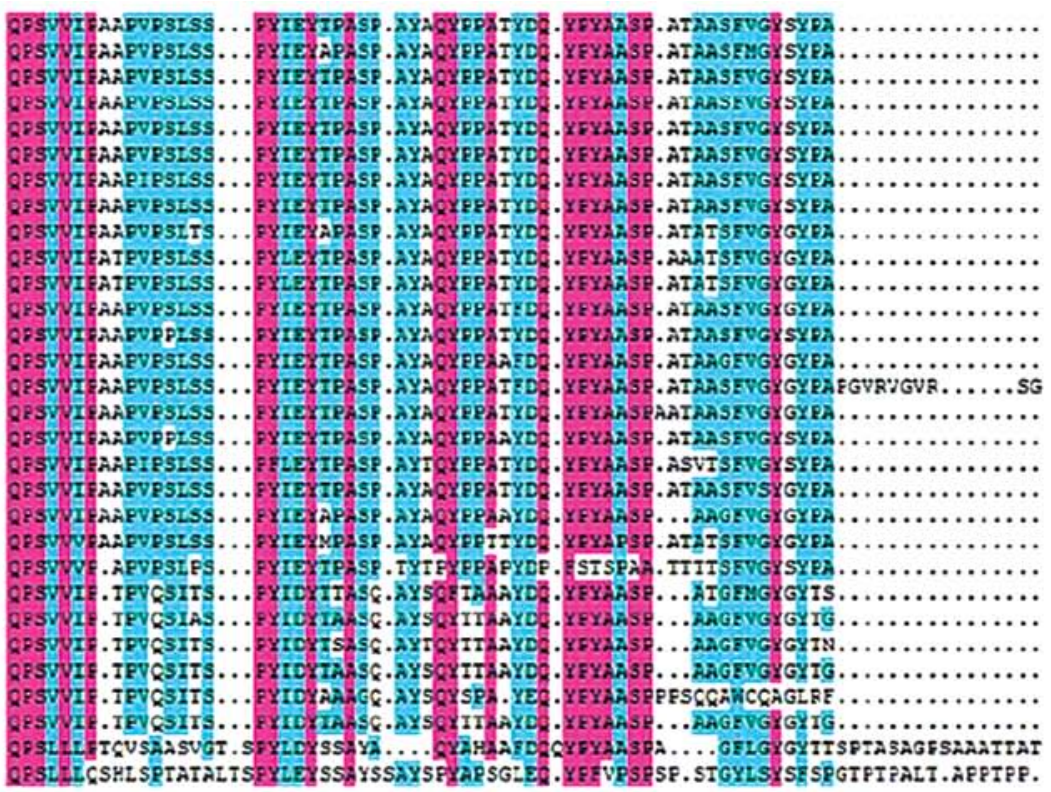

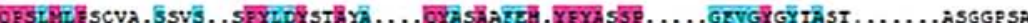

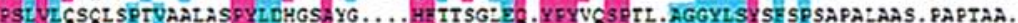

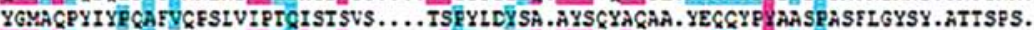

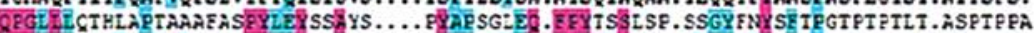

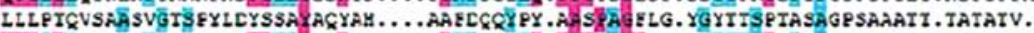

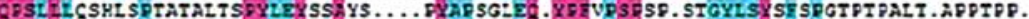

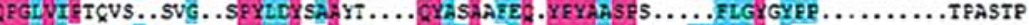

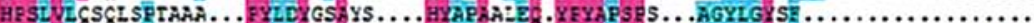

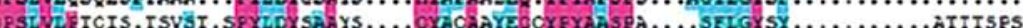

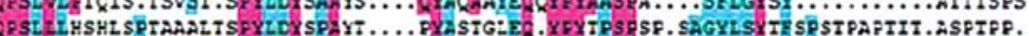

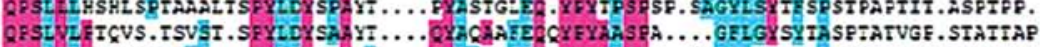

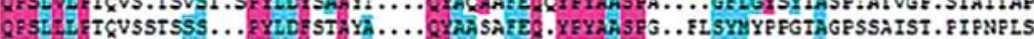

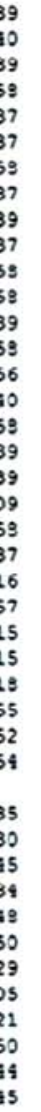

Figure 1. Continued. (B) Alignment of RNPC1 in vertebrates from position 152-239. All the RNPC1 gene and protein sequences were collected from Ensembl and checked using the BLAST tool at NCBI. The complete RNPC1 gene was identified in the human, bushbaby, chimpanzee, macaque, gorilla, olive baboon, vervet-AGM, guinea pig, mouse, rat, cow, dog, ferret, hedgehog, armadillo, elephant, lesser hedgehog tenrec, anole lizard, chicken, Chinese softshell turtle, duck, Amazon molly, flycatcher, cave fish, fugu, medaka, platyfish, spotted gar, stickleback, tilapia, tetraodon and zebrafish genomes. 


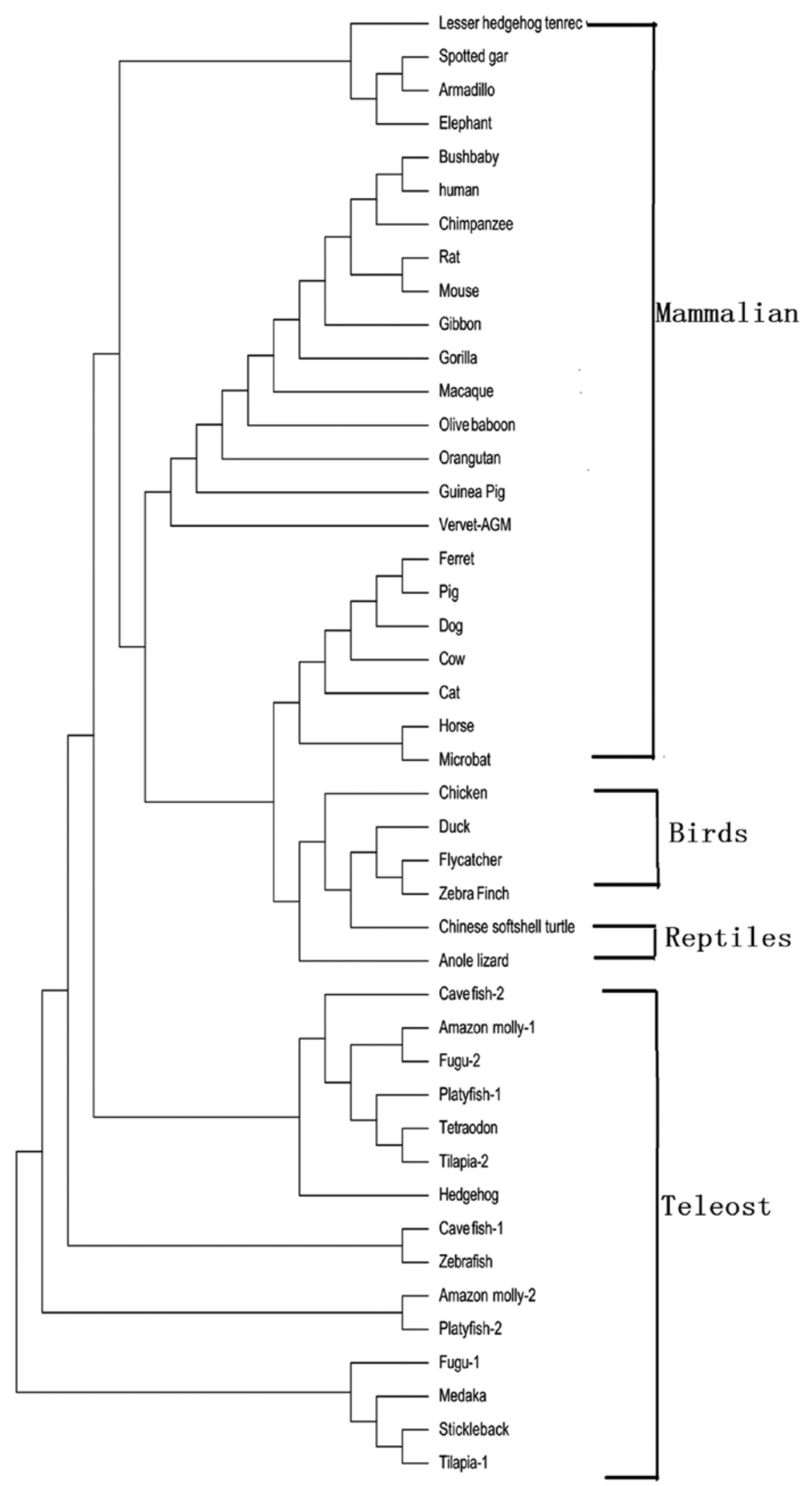

Figure 2. The phylogenetic tree was constructed according to the protein-coding sequences of RNPC1 using the maximum likelihood method. The RNPC1 gene from the mammalian, bird, reptile and teleost lineages formed species-specific clusters.

was constructed according to the protein-coding sequences of RNPC1, using the maximum likelihood method; the RNPC1 gene from the mammalian, bird, reptile and teleost lineages formed species-specific clusters (Fig. 2). The exon-intron data 
Table I. Exon and intron lengths of RNPC1.

\begin{tabular}{|c|c|c|c|c|c|c|c|c|c|c|}
\hline Species & Exon 1 & Intron 1 & Exon 2 & Intron 2 & Exon 3 & Intron 3 & Exon 4 & Intron 4 & Exon 5 & Total exons \\
\hline Human & 237 & 835 & 124 & 501 & 55 & 14209 & 304 & & & 720 \\
\hline Bushbaby & 240 & 842 & 124 & 430 & 55 & 11713 & 304 & & & 723 \\
\hline Chimpanzee & 720 & & & & & & & & & 720 \\
\hline Macaque & 237 & 816 & 124 & 503 & 55 & 13671 & 298 & & & 714 \\
\hline Olive baboon & 237 & 835 & 124 & 508 & 55 & 13677 & 298 & & & 714 \\
\hline Vervet-AGM & 237 & 841 & 124 & 505 & 55 & 13836 & 298 & & & 714 \\
\hline Mouse & 0 & 1110 & 231 & 521 & 124 & 411 & 55 & 10124 & 304 & 714 \\
\hline Rat & 118 & 489 & 55 & 9816 & 300 & & & & & 473 \\
\hline Guinea Pig & 237 & 748 & 124 & 442 & 55 & 10426 & 301 & & & 717 \\
\hline Cow & 237 & 753 & 124 & 483 & 55 & 12228 & 304 & & & 720 \\
\hline Pig & 237 & 778 & 124 & 559 & 55 & 11296 & 304 & & & 720 \\
\hline Armadillo & 168 & 747 & 124 & 399 & 55 & 12317 & 283 & & & 630 \\
\hline Amazon molly-1 & 213 & 4109 & 141 & 1707 & 56 & 6429 & 349 & & & 759 \\
\hline Amazon molly-2 & 222 & 4039 & 124 & 2832 & 55 & 13455 & 364 & & & 765 \\
\hline Cave fish-2 & 213 & 2209 & 124 & 151 & 55 & 4745 & 316 & & & 708 \\
\hline Fugu-1 & 171 & 789 & 124 & 1405 & 55 & 5561 & 340 & & & 690 \\
\hline Medaka & 171 & 2679 & 124 & 2251 & 55 & 13729 & 355 & & & 705 \\
\hline Platyfish-2 & 222 & 4066 & 124 & 2973 & 55 & 15548 & 352 & & & 753 \\
\hline Spotted gar & 210 & 2827 & 124 & 2302 & 55 & 6210 & 301 & & & 690 \\
\hline Stickleback & 171 & 904 & 124 & 1223 & 55 & 6070 & 187 & 54 & 81 & 618 \\
\hline Tetraodon & 174 & 1629 & 124 & 269 & 55 & 3386 & 214 & 27 & 99 & 666 \\
\hline Zebrafish & 211 & 13848 & 124 & 12313 & 55 & 17086 & 247 & 4 & 102 & 739 \\
\hline
\end{tabular}

collected from the ENSEMBL database are shown in Table I and Fig. 3. In the majority of vertebrates, the RNPC1 gene exhibited exon-intron conservation, with 4 exons and 3 introns, with similar sizes for each exon and intron (Table I). However, there were 5 exons and 4 introns in the RNPC1 gene in the mouse and 3 fish species (stickleback, tetraodon and zebrafish). Thus, the intron deletions in the RNPC1 gene may occur during the evolutionary process of these 3 species of fish. Furthermore, site-specific tests for positive selection were performed for the vertebrate, mammalian, primate, and mammalian excluding primate, rodent and teleost lineages. We were unable to identify any site which was under positive selection by the M7 and M8 models in the RNPC1 protein. It seemed that RNPC1 in vertebrates was under purifying selection (data not shown).

Expression profile of the human RNPCl gene. The investigation of the available microarray data and virtual northern blot analysis, we revealed the predominant expression of RNPC1 in bone marrow, whole blood, lymph node, thymus, brain, cerebellum, retina, spinal cord, heart, smooth muscle, skeletal muscle, small intestine, colon, adipocyte, kidneys, liver, lungs, pancreas, thyroid, salivary gland, skin, breast, ovaries, uterus, placenta, prostate and testes. When we searched the PrognoScan database, we found that human RNPC1 was also expressed in bladder, blood, brain, breast, colorectal, eye, head and neck, lung, ovarian, skin and soft tissue cancer.

Comparative genomic analysis of the human RNPC1 gene. The sex determining region Y (SRY)-box 5 (Sox5), runt- related transcription factor 3 (RUNX3), CCAAT displacement protein 1 (CUTL1), v-rel avian reticuloendotheliosis viral oncogene homolog (Rel)A, peroxisome proliferator-activated receptor $\gamma$ isoform 2 (PPAR $\gamma 2$ ) and activating transcription factor 6 (ATF6) regulatory transcription factor binding sites were identified in the upstream (promoter) region of the RNPC1 gene.

Identification of functionally relevant SNPs in the human RNPC1 gene and somatic mutations in human cancer. A total of 429 SNPs were identified in the human RNPC1 gene. Of these, 34 SNPs were functionally relevant, including 14 SNPs causing missense mutations, 8 exonic splicing enhancer SNPs and 12 SNPs causing nonsense mutations (Table II). By searching the COSMIC database, we identified 30 somatic mutations of RNPC1 in 10,148 cancer samples (Table III).

\section{Meta-analysis of the prognostic value of the human RNPCI} gene in cancer. When provided with the specific gene, PrognoScan displays a summary (in table format) of tests for the gene, with columns for the dataset, cancer type, subtype, endpoint, cohort, contributor, array type, probe ID, number of patients, optimal cut-point, Pmin and Pcor. Among the databases which detected the expression of the RNPC1 gene, an association between the expression of the RNPC1 gene and cancer prognosis was noted in 14 of the 94 tests (blood cancer $2 / 9$, brain cancer $1 / 5$, breast cancer $3 / 30$, colorectal cancer $1 / 9$, eye $1 / 1$, head and neck cancer $0 / 1$, lung cancer $5 / 24$, ovarian cancer $1 / 10$, skin cancer $0 / 1$ and soft tissue cancer $0 / 1$ ), 

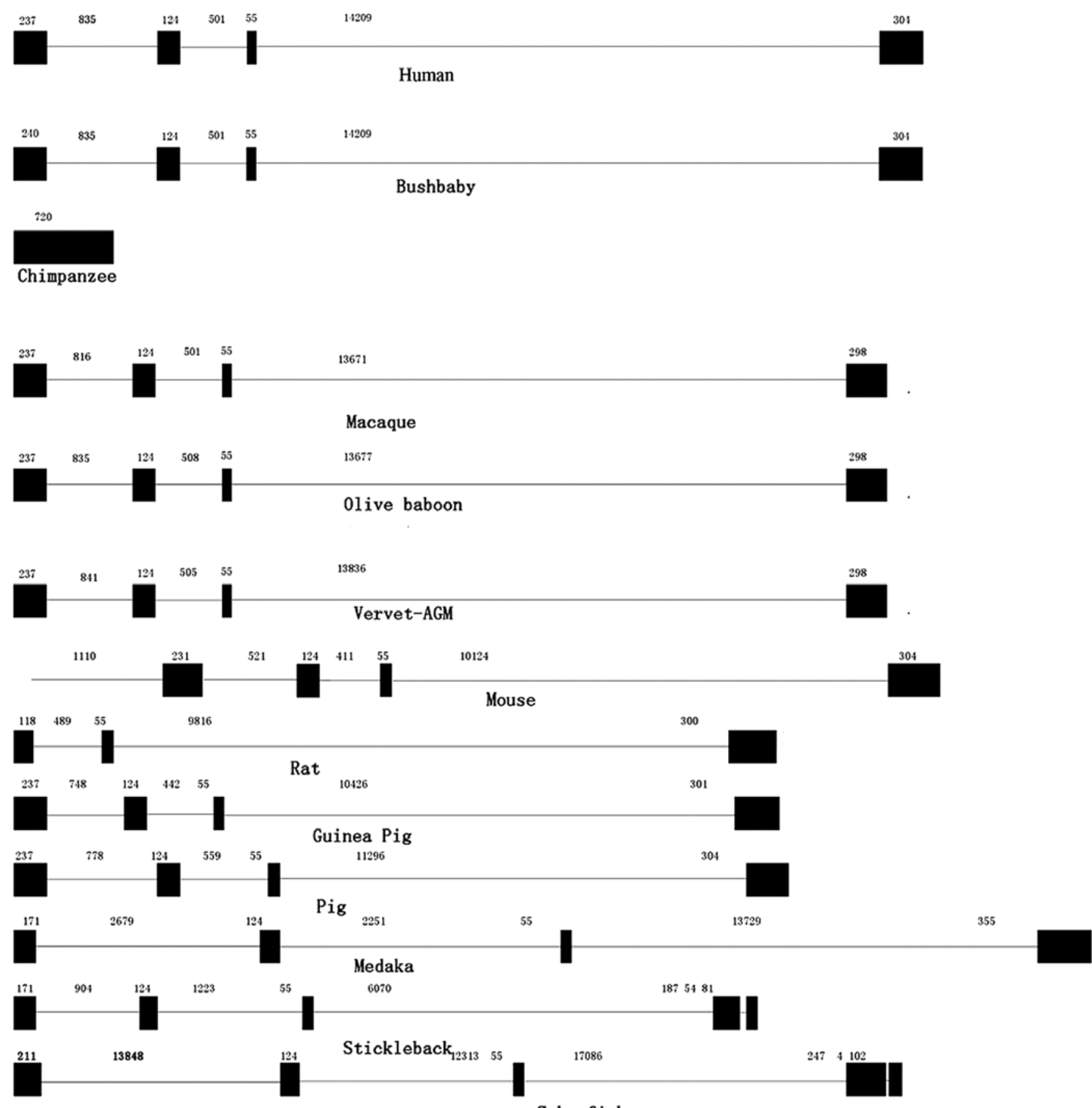

Zebrafish

Figure 3. Exon-intron conservation among the RNPC1 gene. In the majority of vertebrates, the RNPC1 gene showed a similar exon-intron conservation, namely 4 exons and 3 introns, with similar sizes for each exon and intron (Table I). However, there are 5 exons and 4 introns in the RNPC1 gene in the mouse and 3 fish species (stickleback, tetraodon and zebrafish).

with a 5\% significance level (Table IV). As regards blood, colorectal and eye cancer, a correlation between the decreased expressino of the RNPC1 gene and poor survival was observed. However, a higher expression of the RNPC1 gene was found to correlated with a poor survival in patients with brain and ovarian cancer. Of the 3 breast cancer cases, a lower expression of the RNPC1 gene, which correlated with poor survival, was observed in 2 cases (E-TABM-158 and GSE7849), while a higher expression of the RNPC1 gene correlated with a poor survival in the case of GSE11121. Of the lung cancer cases, a lower expression of the RNPC1 gene, which correlated with poor survival, was noted in 2 cases (GSE31210 and GSE31211), while a higher expression of the RNPC1 gene correlated with poor survival in 3 cases (HARVARD-LC, GSE4716-GPL3694 and Jacob-00182-CANDF) cases.

\section{Discussion}

RNPC1 (also known as RBM38), is an RBP that contains one RRM domain. It is expressed as two isoforms, RNPCla and 
Table II. Functionally relevant SNPs in the human RNPC1 gene.

\begin{tabular}{|c|c|c|c|c|}
\hline SNP ID & Chr 20 position sequence & Sequence & Type & Amino acid change \\
\hline rs150246007 & $55982673(+)$ & CCCGTC/TGCTGT & mis & S L \\
\hline rs201278266 & $55982720(+)$ & CCTACA/GCCCAG & $\operatorname{mis}$ & T A \\
\hline rs201875738 & $55982772(+)$ & GCCTGC/TCACGG & mis & A V \\
\hline rs199521379 & $55982775(+)$ & TGCCAC/TGGCTG & mis & T M \\
\hline rs201066490 & 55982813(+) & CCGCCA/GTGCCC & mis & M V \\
\hline rs201744631 & $55982843(+)$ & CACCCA/GCGGGC & mis & T A \\
\hline rs16980970 & $55982858(+)$ & CTTTCG/CTGCAG & mis & L V \\
\hline rs 1065289 & $55982781(+)$ & GGCTGC/ACAGCT & mis & D A \\
\hline rs369246420 & $55982844(+)$ & ACCCGC/TGGGCA & mis & $\mathrm{AV}$ \\
\hline rs373452137 & $55982615(+)$ & ACTACA/GTCTAC & $\operatorname{mis}$ & I V \\
\hline rs377081682 & $55982714(+)$ & GCCCGG/TCCTAC & mis & A S \\
\hline rs368322258 & $55982789(+)$ & GCTTCA/GTGGGC & mis & M V \\
\hline rs10652881 & 55982715(+) & CCCGGC/TCTACG & $\operatorname{mis}$ & $\mathrm{AV}$ \\
\hline rs 1065290 & $55982817(+)$ & CGTGCC/ACCAGG & mis & H P \\
\hline rs11546710 & $55983073(+)$ & AGAGAC/TGGCTT & ese & \\
\hline rs6128022 & $55983476(+)$ & TCCCAG/AGCGCA & ese & \\
\hline rs8126441 & 55983505(+) & GGGGCC/AGCCGG & ese & \\
\hline rs3829703 & $55983509(-)$ & TTGGCC/TGGCGG & ese & \\
\hline rs11546713 & $55984212(-)$ & CCCCCA/GCCCTC & ese & \\
\hline rs 1065292 & $55983556(+)$ & TTTTTC/TTTGTA & ese & \\
\hline rs1052752 & 55983512(+) & CCGGCC/AAAAGG & ese & \\
\hline rs3207621 & $55983521(+)$ & GGCCCC/TTTTCC & ese & \\
\hline rs141028132 & $55982671(+)$ & GTCCCG/ATCGCT & syn & $\mathrm{P}$ \\
\hline rs201839752 & $55982683(+)$ & TCCTCA/GCCCTA & syn & $S$ \\
\hline rs115516069 & 55982695(+) & ATTGAG/ATACAC & syn & $\mathrm{E}$ \\
\hline rs200910302 & $55982719(+)$ & GCCTAC/TGCCCA & syn & $\mathrm{Y}$ \\
\hline rs199953546 & $55982758(+)$ & CCATAC/TGCCGC & syn & $\mathrm{Y}$ \\
\hline rs143107197 & $55982812(+)$ & GCCGCC/TGTGCC & syn & A \\
\hline rs373297597 & $55982875(+)$ & GCGCCA/GCAGCT & syn & $\mathrm{P}$ \\
\hline rs373492567 & $55982887(+)$ & CAGCCA/TGACAG & syn & $\mathrm{P}$ \\
\hline rs202004284 & 55982704(+) & ACGCCG/AGCCAG & syn & $\mathrm{P}$ \\
\hline rs376442730 & $55982872(+)$ & CAGGCA/GCCGCA & syn & A \\
\hline rs377524807 & 55982644(+) & CCCAGC/TGTGGT & syn & $\mathrm{S}$ \\
\hline rs374582705 & $55982713(+)$ & AGCCCA/GGCCTA & syn & $\mathrm{P}$ \\
\hline
\end{tabular}

A total of 429 single nucleotide polymorphisms (SNPs) were identified in the human RNPC1 gene. Of these, 34 SNPs were functionally relevant, including 14 SNPs causing missense (mis) mutations, 8 exonic splicing enhancer (ese) SNPs and 12 SNPs causing nonsense mutations. Chr, chromosome.

RNPC1b (6). RNPC1 is a direct target of p53 and can interact with other members of the p53 family; it can stabilize p21 and p73 transcripts and destabilize p63 transcripts. It can also bind and stabilize the mRNA of the CDK inhibitor, p21, thereby inducing cell cycle arrest in the G1 phase $(7,8)$. RNPC1 also binds and stabilizes the mRNA of another RBP HuR, which in turn facilitates RNPC1-mediated growth arrest (7). In the present study, the complete RNPC1 gene was identified in the human, bushbaby, chimpanzee, macaque, gorilla, olive baboon, vervet-AGM, guinea pig, mouse, rat, cow, dog, ferret, hedgehog, armadillo, elephant, lesser hedgehog tenrec, anole lizard, chicken, Chinese softshell turtle, duck, Amazon molly, flycatcher, cave fish, Fugu, medaka, platyfish, spotted gar, stickleback, tilapia, tetraodon and zebrafish genomes, suggesting that RNPC1 exists in all types of vertebrates, including fish, amphibians, birds and mammals. In the different genomes, the gene had a similar organization, namely 4 exons/3 introns, and all the genetic loci were syntenically conserved. The phylogenetic tree revealed that the RNPC1 gene from the mammalian, bird, reptile and teleost lineage formed species-specific clusters. As observed from the alignment and phylogenetic tree, RNPC1 in mammals is conserved among vertebrate genomes, 
Table III. Somatic mutations of RNPC1 in cancer tissue.

\begin{tabular}{|c|c|c|c|c|c|}
\hline $\begin{array}{l}\text { Position } \\
\text { (AA) }\end{array}$ & $\begin{array}{l}\text { Mutation } \\
\text { (CDS) }\end{array}$ & $\begin{array}{c}\text { Mutation } \\
\text { (amino acid) }\end{array}$ & $\begin{array}{c}\text { Mutation ID } \\
\text { (COSM) }\end{array}$ & Count & Mutation type \\
\hline 19 & c. $55 \mathrm{G}>\mathrm{C}$ & p.A19P & COSM1412673 & 2 & Substitution - missense \\
\hline 20 & c.56_57insC & p.A20fs 70 & COSM3724433 & 2 & Insertion - frameshift \\
\hline 49 & c. $146 \mathrm{C}>\mathrm{G}$ & p.S49W & COSM3963694 & 1 & Substitution - missense \\
\hline 55 & c. $163 \mathrm{G}>\mathrm{C}$ & p.E55Q & COSM397137 & 1 & Substitution - missense \\
\hline 78 & c. $234 \mathrm{C}>\mathrm{T}$ & p.G78G & COSM724075 & 1 & Substitution - coding silent \\
\hline 83 & c. $249 \mathrm{C}>\mathrm{T}$ & p.A83A & COSM1165242 & 1 & Substitution - coding silent \\
\hline 89 & c. $265 \mathrm{G}>\mathrm{A}$ & p.E89K & COSM724074 & 1 & Substitution - missense \\
\hline 89 & c. $266 \mathrm{~A}>\mathrm{G}$ & p.E89G & COSM117504 & 1 & Substitution - missense \\
\hline 97 & c. $290 \mathrm{C}>\mathrm{T}$ & p.P97L & COSM224597 & 1 & Substitution - missense \\
\hline 109 & c. $325 \mathrm{G}>\mathrm{A}$ & p.A109T & COSM1412674 & 1 & Substitution - missense \\
\hline 112 & c. $336 \mathrm{C}>\mathrm{T}$ & p.G112G & COSM192074 & 1 & Substitution - coding silent \\
\hline 116 & c. $346 \mathrm{C}>\mathrm{T}$ & p.R116W & COSM1579588 & 1 & Substitution - missense \\
\hline 116 & c. $347 \mathrm{G}>\mathrm{A}$ & p.R116Q & COSM724073 & 1 & Substitution - missense \\
\hline 120 & c. $359 \mathrm{C}>\mathrm{T}$ & p.T120M & COSM1028363 & 1 & Substitution - missense \\
\hline 131 & c. $392 \mathrm{C}>\mathrm{G}$ & p.P131R & COSM3405224 & 1 & Substitution - missense \\
\hline 132 & c. $395 \mathrm{C}>\mathrm{G}$ & p.T132S & COSM3363328 & 1 & Substitution - missense \\
\hline 139 & c. $415 \mathrm{G}>\mathrm{A}$ & p.G139R & COSM125790 & 1 & Substitution - missense \\
\hline 147 & c. $441 \mathrm{~A}>\mathrm{C}$ & p.P147P & COSM4134683 & 1 & Substitution - coding silent \\
\hline 150 & c. $450 \mathrm{C}>\mathrm{T}$ & p.I150I & COSM1565701 & 1 & Substitution - coding silent \\
\hline 160 & c. $478 \mathrm{G}>\mathrm{A}$ & p.A160T & COSM1412675 & 1 & Substitution - missense \\
\hline 163 & c. $487 \mathrm{C}>\mathrm{T}$ & p.P163S & COSM3548089 & 1 & Substitution - missense \\
\hline 168 & c. $.502 \mathrm{C}>\mathrm{T}$ & p.P168S & COSM3548090 & 1 & Substitution - missense \\
\hline 172 & c. $.515 \mathrm{~A}>\mathrm{G}$ & p.Y172C & COSM4099709 & 1 & Substitution - missense \\
\hline 174 & c. $521 \mathrm{C}>\mathrm{T}$ & p.P174L & COSM1412676 & 1 & Substitution - missense \\
\hline 176 & c. $527 \mathrm{G}>\mathrm{A}$ & p.S176N & COSM270012 & 1 & Substitution - missense \\
\hline 193 & c. $577 \mathrm{G}>\mathrm{A}$ & p.A193T & COSM3770849 & 1 & Substitution - missense \\
\hline 193 & c. $579 \mathrm{C}>\mathrm{T}$ & p.A193A & COSM3548091 & 1 & Substitution - coding silent \\
\hline 210 & c. $628 \mathrm{G}>\mathrm{A}$ & p.A210T & COSM4099710 & 1 & Substitution - missense \\
\hline 220 & c. $659 \mathrm{C}>\mathrm{T}$ & p.P220L & COSM3911642 & 1 & Substitution - missense \\
\hline 225 & c. $675 \mathrm{C}>\mathrm{T}$ & p.F225F & COSM263280 & 1 & Substitution - coding silent \\
\hline
\end{tabular}

suggesting that the function of RNPC1 plays an important physiological role in all vertebrates during the evolution process.

The investigation of available microarray data and virtual northern blot analysis confirmed the predominant expression of RNPC1 in the bone marrow, whole blood, the lymph node, thymus, brain, cerebellum, retina, spinal cord, heart, smooth muscle, skeletal muscle, small intestine, colon, adipocyte, kidneys, liver, lungs, pancreas, thyroid, salivary gland, skin, breast, ovaries, uterus, placenta, prostate and testes. Thus, RNPC1 is widely expressed in a number of tissues and organs. A total of 429 SNPs were identified in the human RNPC1 gene. Of these, 34 SNPs were functionally relevant, including 14 SNPs causing missense mutations, 8 exonic splicing enhancer SNPs and 12 SNPs causing nonsense mutations, which may affect the multiple functions of RNPC1. However, the effects of these SNPs on RNPC1 physiological and pathological functions require further investigation.
RNPC1 was originally recognized as an oncogene, and was frequently found to be amplified in prostate $(14,15)$, ovarian (16) and colorectal cancer $(17,18)$, chronic lymphocytic leukemia (19), colon carcinoma (20), esophageal cancer (21), dog lymphomas (13) and breast cancer (22-24). In our previous study, we found that RNPC1 played a tumor suppressor role role in breast cancer (40). In the present study, we first noted that RNPC1 was indeed expressed in bladder, blood, brain, breast, colorectal, eye, head and neck, lung, ovarian, skin and soft tissue cancer. Out of 94 tests, 14 revealed an association between RNPC1 gene expression and cancer prognosis (blood $2 / 9$, brain $1 / 5$, breast $3 / 30$, colorectal $1 / 9$, eye $1 / 1$, head and neck $0 / 1$, lung $5 / 24$, ovarian $1 / 10$, skin $0 / 1$ and soft tissue cancer $0 / 1)$. It is important to note that the association between the expression of RNPC1 and prognosis varied in different types of cancer, and even in the same type of cancer from different databases. This suggests that the function of RNPC1 in these tumors may be multidimensional, and that RNPC1 is 
Table IV. Dataset content from PrognoScan demonstrating an association between the expression of the RNPC1 gene and cancer prognosis.

\begin{tabular}{|c|c|c|c|c|c|c|c|c|}
\hline Database & Case type & Subsyte & $\begin{array}{l}\text { No. of } \\
\text { patients }\end{array}$ & Endpoint & $\begin{array}{l}\text { Cut- } \\
\text { point }\end{array}$ & P-value & Prognosis & Refs. \\
\hline GSE12417-GPL570 & Blood cancer & AML & 79 & Overall survival & 0.15 & 0.001223 & 1 & (57) \\
\hline GSE12417-GPL96 & Blood cancer & AML & 163 & Overall survival & 0.39 & 0.035113 & 1 & $(57)$ \\
\hline GSE4271-GPL96 & Brain cancer & Astrocytoma & 77 & Overall survival & 0.82 & 0.003856 & 2 & $(58)$ \\
\hline GSE7849 & Breast cancer & & 76 & Disease-free survival & 0.3 & 0.030908 & 1 & $(59)$ \\
\hline GSE11121 & Breast cancer & & 200 & $\begin{array}{l}\text { Distant metastasis-free } \\
\text { survival }\end{array}$ & 0.82 & 0.008577 & 2 & (60) \\
\hline E-TABM-158 & Breast cancer & & 117 & Disease-specific survival & 0.7 & 0.035878 & 1 & (61) \\
\hline GSE17537 & Colorectal cancer & & 55 & Overall survival & 0.11 & 0.02856 & 1 & $(62)$ \\
\hline GSE22138 & Eye cancer & Uveal melanoma & 63 & $\begin{array}{l}\text { Distant metastasis-free } \\
\text { survival }\end{array}$ & 0.33 & 0.018941 & 1 & (63) \\
\hline jacob-00182-CANDF & Lung cancer & Adenocarcinoma & 82 & Overall survival & 0.82 & 0.020135 & 2 & (64) \\
\hline HARVARD-LC & Lung cancer & Adenocarcinoma & 84 & Overall survival & 0.69 & 0.004177 & 2 & (65) \\
\hline GSE31210 & Lung cancer & Adenocarcinoma & 204 & Relapse-free survival & 0.51 & 0.001557 & 1 & (66) \\
\hline GSE31211 & Lung cancer & Adenocarcinoma & 204 & Overall survival & 0.34 & 0.000939 & 1 & (66) \\
\hline GSE4716-GPL3694 & Lung cancer & NSCLC & 50 & Overall survival & 0.82 & 0.044441 & 2 & (67) \\
\hline DUKE-OC & Ovarian cancer & & 133 & Overall survival & 0.85 & 0.010709 & 2 & (68) \\
\hline
\end{tabular}

Of the 94 tests, in 14, we noted an association between the expression of the RNPC1 gene and cancer prognosis (blood cancer 2/9, brain cancer 1/5, breast cancer $3 / 30$, colorectal cancer $1 / 9$, eye cancer $1 / 1$, head and neck cancer $0 / 1$, lung cancer $5 / 24$, ovarian cancer $1 / 10$, skin cancer $0 / 1$ and soft tissue cancer 0/1) with a 5\% significance level. AML, acute myeloid leukemia; NSCLC, non-small cell lung cancer.

not just a tumor suppressor or promoter. Moreover, we identified 30 somatic mutations of RNPC1 in cancer tissues in the present study. Further investigation is required to elucidate the mechanisms through which these mutations affect tumor formation. The mechanisms underlying the role of RNPC1 in the process of these tumors may be involve the mRNA stabilizion of oncogenes or anti-oncogenes, such as p53 (13), p63 (11), MDM2 (12), p73 (9), HuR (7) and p21 (6). However, the mechanisms underlying the role of RNPC1 in the developmental process of these tumors require further investigation.

The Sox5, RUNX3, CUTL1, RelA, CCAAT-enhancerbinding protein (C/EBP) $\alpha$, c-Ets-1, PPAR $\gamma 2$ and ATF6 regulatory transcription factor binding sites were identified in the upstream (promoter) region of the RNPC1 gene. Sox 5 plays a role in the regulation of embryonic development and in the determination of cell fate. It can function as a transcriptional regulator after forming a protein complex with other proteins. It has a negative effect on cell proliferation in some cell types and functions as a target of microRNAs $(41,42)$. RUNX3 encodes a member of the runt domain-containing family of transcription factors. A heterodimer of this protein and a $\beta$ subunit forms a complex that binds to the core DNA sequence 5'-PYGPYGGT-3' found in a number of enhancers and promoters, and can either activate or suppress transcription. It functions as a tumor suppressor and is frequently deleted or transcriptionally silenced in cancer (43-46). CUTL1 is a transcription factor which plays a role in development and multiple physiological processes. Emerging evidence indicates that CUTL1 is not only involved in developmental events, but also in pathological processes, such as tumorigenesis and multiple signal transduction pathways of cancer $(47,48)$. RelA is a subunit of the nuclear factor $(\mathrm{NF}-\kappa \mathrm{B}) \mathrm{p} 65$. NF- $\mathrm{NB}$ is an ubiquitous transcription factor which plays a role in several biological processes. NF- $\kappa \mathrm{B}$ is composed of NFKB1 or NFKB2 bound to either REL, RELA or RELB. NF- $\kappa B$ is a pleiotropic transcription factor present in almost all cell types and is the endpoint of a series of signal transduction events that are initiated by a vast array of stimuli related to a number of biological processes, such as inflammation, immunity, differentiation, cell growth, tumorigenesis and apoptosis (49-52). $\mathrm{C} / \mathrm{EBP} \alpha$ is required for the proper control of adipogenesis, glucose metabolism, granulocytic differentiation, lung development and the development of various types of cancer $(53,54)$. c-Ets-1 is known to play an important role in various biological processes, such as development, differentiation, proliferation, apoptosis, migration, tissue remodeling, invasion and angiogenesis in a variety of cell types, including B cells, endothelial cells, fibroblasts and neoplastic cells $(55,56)$. These tumor-related transcriptional factors may be involved in the effects of RNPC1 in tumors (14-24).

In conclusion, integrative genomic analyses of RNPC1 and its role in cancer prediction provide a powerful tool for the evaluation of RNPC1 as a potential tumor markers and therapeutic targets in cancer research.

\section{Acknowledgements}

The present study was supported by grants from the National Natural Science Foundation of China (nos. 81272916 and 
81202077), the Key Project of Jiangsu Provincial Health (H201110 to Q.D.), the Project of Jiangsu Province Traditional Chinese Medicine Bureau (LZ11084), the 'Six Talents Peak' projects of Jiangsu Province (to T.-S.X.), the Qinglan project of Jiangsu Province (to T.-S.X.) and a project funded by the Priority Academic Program Development of Jiangsu higher Education Institutions (PAPD).

\section{References}

1. Kim MY, Hur $\mathbf{J}$ and Jeong S: Emerging roles of RNA and RNA-binding protein network in cancer cells. BMB Rep 42: 125-130, 2009.

2. Krecic AM and Swanson MS: hnRNP complexes: composition, structure, and function. Curr Opin Cell Biol 11: 363-371, 1999.

3. Dreyfuss G, Matunis MJ, Piñol-Roma S and Burd CG: hnRNP proteins and the biogenesis of mRNA. Annu Rev Biochem 62 289-321, 1993.

4. Audic $\mathrm{Y}$ and Hartley RS: Post-transcriptional regulation in cancer. Biol Cell 96: 479-498, 2004.

5. Yisraeli JK: VICKZ proteins: a multi-talented family of regulatory RNA-binding proteins. Biol Cell 97: 87-96, 2005.

6. Shu L, Yan W and Chen X: RNPC1, an RNA-binding protein and a target of the $\mathrm{p} 53$ family, is required for maintaining the stability of the basal and stress-induced p21 transcript. Genes Dev 20: 2961-2972, 2006.

7. Cho SJ,Zhang J and Chen X: RNPC1 modulates the RNA-binding activity of, and cooperates with, HuR to regulate p 21 mRNA stability. Nucleic Acids Res 38: 2256-2267, 2010.

8. Miyamoto S, Hidaka K, Jin D and Morisaki T: RNA-binding proteins $\mathrm{Rbm} 38$ and $\mathrm{Rbm} 24$ regulate myogenic differentiation via p21-dependent and -independent regulatory pathways. Genes Cells 14: 1241-1252, 2009.

9. Yan W, Zhang J, Zhang Y, Jung YS and Chen X: p73 expression is regulated by RNPC1, a target of the p53 family, via mRNA stability. Mol Cell Biol 32: 2336-2348, 2012.

10. Yin T, Cho SJ and Chen X: RNPC1, an RNA-binding protein and a p53 target, regulates macrophage inhibitory cytokine-1 (MIC-1) expression through mRNA stability. J Biol Chem 288 23680-23686, 2013

11. Zhang J, Jun Cho S and Chen X: RNPC1, an RNA-binding protein and a target of the p53 family, regulates p63 expression through mRNA stability. Proc Natl Acad Sci USA 107: 9614-9619, 2010.

12. Xu E, Zhang J and Chen X: MDM2 expression is repressed by the RNA-binding protein RNPC1 via mRNA stability. Oncogene 32: 2169-2178, 2013

13. Zhang J, Cho SJ, Shu L, Yan W, Guerrero T, Kent M, Skorupski K, Chen $\mathrm{H}$ and Chen X: Translational repression of $\mathrm{p} 53$ by RNPC1, a p53 target overexpressed in lymphomas. Genes Dev 25 . $1528-1543,2011$.

14. Zheng SL, Xu J, Isaacs SD, Wiley K, Chang B, Bleecker ER, Walsh PC, Trent JM, Meyers DA and Isaacs WB: Evidence for a prostate cancer linkage to chromosome 20 in 159 hereditary prostate cancer families. Hum Genet 108: 430-435, 2001.

15. Bar-Shira A, Pinthus JH, Rozovsky U, Goldstein M, Sellers WR, Yaron Y, Eshhar Z and Orr-Urtreger A: Multiple genes in human $20 \mathrm{q} 13$ chromosomal region are involved in an advanced prostate cancer xenograft. Cancer Res 62: 6803-6807, 2002.

16. Tanner MM, Grenman S, Koul A, Johannsson O, Meltzer P, Pejovic T, Borg A and Isola JJ: Frequent amplification of chromosomal region 20q12-q13 in ovarian cancer. Clin Cancer Res 6: $1833-1839,2000$.

17. Korn WM, Yasutake T, Kuo WL, Warren RS, Collins C, Tomita M, Gray J and Waldman FM: Chromosome arm 20q gains and other genomic alterations in colorectal cancer metastatic to liver, as analyzed by comparative genomic hybridization and fluorescence in situ hybridization. Genes Chromosomes Cancer 25: 82-90, 1999.

18. Knösel T, Schlüns K, Stein U, Schwabe H, Schlag PM, Dietel M and Petersen I: Genetic imbalances with impact on survival in colorectal cancer patients. Histopathology 43: 323-331, 2003

19. Krackhardt AM, Witzens M, Harig S, Hodi FS, Zauls AJ, Chessia M, Barrett P and Gribben JG: Identification of tumorassociated antigens in chronic lymphocytic leukemia by SEREX. Blood 100: 2123-2131, 2002.
20. Carvalho B, Postma C, Mongera S, Hopmans E, Diskin S, van de Wiel MA, van Criekinge W, Thas O, Matthäi A, Cuesta MA, et al: Multiple putative oncogenes at the chromosome 20q amplicon contribute to colorectal adenoma to carcinoma progression. Gut 58: 79-89, 2009.

21. Hötte GJ, Linam-Lennon N, Reynolds JV and Maher SG: Radiation sensitivity of esophageal adenocarcinoma: the contribution of the RNA-binding protein RNPC1 and p21-mediated cell cycle arrest to radioresistance. Radiat Res 177: 272-279, 2012.

22. Ginestier C, Cervera N, Finetti P, Esteyries S, Esterni B, Adélaïde J, Xerri L, Viens P, Jacquemier J, Charafe-Jauffret E, et al: Prognosis and gene expression profiling of 20q13-amplified breast cancers. Clin Cancer Res 12: 4533-4544, 2006.

23. Letessier A, Sircoulomb F, Ginestier C, Cervera N, Monville F, Gelsi-Boyer V, Esterni B, Geneix J, Finetti P, Zemmour C, et al: Frequency, prognostic impact, and subtype association of $8 \mathrm{p} 12$, 8q24, 11q13, 12p13, 17q12, and 20q13 amplifications in breast cancers. BMC Cancer 6: 245, 2006.

24. Xue JQ, Xia TS, Liang XQ, Zhou W, Cheng L, Shi L, Wang Y and Ding Q: RNA-binding protein RNPC1: Acting as a tumor suppressor in breast cancer. BMC Cancer 14: 322, 2014.

25. Feldstein O, Ben-Hamo R, Bashari D, Efroni S and Ginsberg D: RBM38 is a direct transcriptional target of E2F1 that limits E2F1-induced proliferation. Mol Cancer Res 10: 1169-1177, 2012.

26. Léveillé N, Elkon R, Davalos V, Manoharan V, Hollingworth D, Oude Vrielink J, le Sage C, Melo CA, Horlings HM, Wesseling J, et al: Selective inhibition of microRNA accessibility by RBM38 is required for p53 activity. Nat Commun 2: 513, 2011.

27. Yang L, Luo $\mathrm{Y}$ and Wei J: Integrative genomic analyses on Ikaros and its expression related to solid cancer prognosis. Oncol Rep 24: 571-577, 2010

28. Yang L, Luo Y, Wei J and He S: Integrative genomic analyses on IL28RA, the common receptor of interferon-lambda1, -lambda2 and -lambda3. Int J Mol Med 25: 807-812, 2010.

29. Yang L, Wei J and He S: Integrative genomic analyses on interferon-lambdas and their roles in cancer prediction. Int $\mathrm{J}$ Mol Med 25: 299-304, 2010

30. Yu H, Yuan J, Xiao C and Qin Y: Integrative genomic analyses of recepteur d'origine nantais and its prognostic value in cancer. Int J Mol Med 31: 1248-1254, 2013.

31. Wang M, Wei X, Shi L, Chen B, Zhao G and Yang H: Integrative genomic analyses of the histamine $\mathrm{H} 1$ receptor and its role in cancer prediction. Int J Mol Med 33: 1019-1026, 2014.

32. Wang B, Chen K, Xu W, Chen D, Tang W and Xia TS: Integrative genomic analyses of secreted protein acidic and rich in cysteine and its role in cancer prediction. Mol Med Rep 10: 1461-1468, 2014.

33. Wang B, Xu W, Tan M, Xiao Y, Yang H and Xia TS: Integrative genomic analyses of a novel cytokine, interleukin-34 and its potential role in cancer prediction. Int J Mol Med 35: 92-102, 2015.

34. Kumar S, Nei M, Dudley J and Tamura K: MEGA: A biologistcentric software for evolutionary analysis of DNA and protein sequences. Brief Bioinform 9: 299-306, 2008.

35. Yang Z: PAML: aA program package for phylogenetic analysis by maximum likelihood. Comput Appl Biosci 13: 555-556, 1997.

36. Yang Z, Nielsen R, Goldman N and Pedersen AM: Codonsubstitution models for heterogeneous selection pressure at amino acid sites. Genetics 155: 431-449, 2000.

37. Forbes SA, Bindal N, Bamford S, Cole C, Kok CY, Beare D, Jia M, Shepherd R, Leung K, Menzies A, et al: COSMIC: Mining complete cancer genomes in the Catalogue of Somatic Mutations in Cancer. Nucleic Acids Res 39: D945-D950, 2011.

38. Parkinson H, Sarkans U, Shojatalab M, Abeygunawardena N, Contrino S, Coulson R, Farne A, Lara GG, Holloway E, Kapushesky M, et al: ArrayExpress - a public repository for microarray gene expression data at the EBI. Nucleic Acids Res 33: D553-D555, 2005.

39. Mizuno H, Kitada K, Nakai K and Sarai A: PrognoScan: a new database for meta-analysis of the prognostic value of genes. BMC Med Genomics 2: 18, 2009

40. Xue JQ, Xia TS, Liang XQ, Zhou W, Cheng L, Shi L, Wang Y and Ding Q: RNA-binding protein RNPC1: Acting as a tumor suppressor in breast cancer. BMC Cancer 14: 322, 2014.

41. Renjie $\mathrm{W}$ and Haiqian L: MiR-132, miR-15a and miR-16 synergistically inhibit pituitary tumor cell proliferation, invasion and migration by targeting Sox 5. Cancer Lett 356: 568-578, 2015.

42. Pei XH, Lv XQ and Li HX: Sox5 induces epithelial to mesenchymal transition by transactivation of Twist1. Biochem Biophys Res Commun 446: 322-327, 2014. 
43. Kang KA, Kim KC, Bae SC and Hyun JW: Oxidative stress induces proliferation of colorectal cancer cells by inhibiting RUNX3 and activating the Akt signaling pathway. Int J Oncol 43: 1511-1516, 2013

44. Xu HW, Ren F, Yu YM and Cai CZ: Runx3 expression in lymph nodes with metastasis is associated with the outcome of gastric cancer patients. Oncol Lett 2: 1275-1279, 2011.

45. Yu GP, Ji Y, Chen GQ, Huang B, Shen K, Wu S and Shen ZY: Application of RUNX3 gene promoter methylation in the diagnosis of non-small cell lung cancer. Oncol Lett 3: 159-162, 2012.

46. Han YX and Liang DY: The role of the tumor suppressor RUNX3 in giant cell tumor of the bone. Int J Oncol 40: 673-678, 2012.

47. Bian J, Li B, Zeng X, Hu H, Hong Y, Ouyang H, Zhang X, Wang Z, Zhu H, Lei P, et al: Mutation of TGF- $\beta$ receptor II facilitates human bladder cancer progression through altered TGF- $\beta 1$ signaling pathway. Int J Oncol 43: 1549-1559, 2013.

48. Liu KC, Lin BS, Zhao M, Wang KY and Lan XP: Cutl1: A potential target for cancer therapy. Cell Signal 25: 349-354, 2013.

49. Claudius AK, Kankipati CS, Kilari RS, Hassan S, Guest K Russell ST, Perry CJ, Stark LA and Nicholl ID: Identification of aspirin analogues that repress NF- $\kappa$ B signalling and demonstrate anti-proliferative activity towards colorectal cancer in vitro and in vivo. Oncol Rep 32: 1670-1680, 2014.

50. Zhang J, Kou YB, Zhu JS, Chen WX and Li S: Knockdown of HMGB1 inhibits growth and invasion of gastric cancer cells through the NF- $\mathrm{BB}$ pathway in vitro and in vivo. Int J Oncol 44: 1268-1276, 2014

51. Guan Z, Ding C, Du Y, Zhang K, Zhu JN, Zhang T, He D, Xu S, Wang $X$ and Fan J: HAF drives the switch of HIF-1 $\alpha$ to HIF-2o by activating the NF- $\kappa \mathrm{B}$ pathway, leading to malignant behavior of T24 bladder cancer cells. Int J Oncol 44: 393-402, 2014.

52. Yu L, Mu Y, Sa N, Wang $\mathrm{H}$ and $\mathrm{Xu} \mathrm{W:} \mathrm{Tumor} \mathrm{necrosis} \mathrm{factor} \alpha$ induces epithelial-mesenchymal transition and promotes metastasis via NF- $\kappa$ B signaling pathway-mediated TWIST expression in hypopharyngeal cancer. Oncol Rep 31: 321-327, 2014.

53. Xue M, Li X, Wu W, Zhang S, Wu S, Li Z and Chen W: Upregulation of long non-coding RNA urothelial carcinoma associated 1 by CCAAT/enhancer binding protein $\alpha$ contributes to bladder cancer cell growth and reduced apoptosis. Oncol Rep 31: 1993-2000, 2014

54. Weng W, Wang M, Xie S, Long Y, Li F, Sun F, Yu Y and Li Z: $\mathrm{YY} 1-\mathrm{C} / \mathrm{EBP} \alpha-\mathrm{miR} 34$ a regulatory circuitry is involved in renal cell carcinoma progression. Oncol Rep 31: 1921-1927, 2014.

55. Wei W, Hu Z, Fu H, Tie Y, Zhang H, Wu Y and Zheng $\mathrm{X}$ : MicroRNA-1 and microRNA-499 downregulate the expression of the ets1 proto-oncogene in HepG2 cells. Oncol Rep 28: 701-706, 2012.

56. Shaikhibrahim Z and Wernert N: ETS transcription factors and prostate cancer: The role of the family prototype ETS-1 (Review). Int J Oncol 40: 1748-1754, 2012.

57. Metzeler KH, Hummel M, Bloomfield CD, Spiekermann K, Braess J, Sauerland MC, Heinecke A, Radmacher M, Marcucci G, Whitman SP, et al; Cancer and Leukemia Group B; German AML Cooperative Group: An 86-probe-set gene-expression signature predicts survival in cytogenetically normal acute myeloid leukemia. Blood 112: 4193-4201, 2008.
58. Phillips HS, Kharbanda S, Chen R, Forrest WF, Soriano RH, Wu TD, Misra A, Nigro JM, Colman H, Soroceanu L, et al: Molecular subclasses of high-grade glioma predict prognosis, delineate a pattern of disease progression, and resemble stages in neurogenesis. Cancer Cell 9: 157-173, 2006.

59. Anders CK, Acharya CR, Hsu DS, Broadwater G, Garman K, Foekens JA, Zhang Y, Wang Y, Marcom K, Marks JR, et al: Age-specific differences in oncogenic pathway deregulation seen in human breast tumors. PLoS One 3: e1373, 2008

60. Schmidt M, Böhm D, von Törne C, Steiner E, Puhl A, Pilch H, Lehr HA, Hengstler JG, Kölbl H and Gehrmann M: The humoral immune system has a key prognostic impact in node-negative breast cancer. Cancer Res 68: 5405-5413, 2008.

61. Jain AN, Chin K, Børresen-Dale AL, Erikstein BK, Eynstein Lonning P, Kaaresen R and Gray JW: Quantitative analysis of chromosomal CGH in human breast tumors associates copy number abnormalities with p53 status and patient survival. Proc Natl Acad Sci USA 98: 7952-7957, 2001.

62. Smith JJ, Deane NG, Wu F, Merchant NB, Zhang B, Jiang A, Lu P, Johnson JC, Schmidt C, Bailey CE, et al: Experimentally derived metastasis gene expression profile predicts recurrence and death in patients with colon cancer. Gastroenterology 138: 958-968, 2010.

63. Laurent C, Valet F, Planque N, Silveri L, Maacha S, Anezo O, Hupe P, Plancher C, Reyes C, Albaud B, et al: High PTP4A3 phosphatase expression correlates with metastatic risk in uveal melanoma patients. Cancer Res 71: 666-674, 2011.

64. Director's Challenge Consortium for the Molecular Classification of Lung Adenocarcinoma; Shedden K, Taylor JM, Enkemann SA, Tsao MS, Yeatman TJ, Gerald WL, Eschrich S, Jurisica I, Giordano TJ, Misek DE, et al: Gene expression-based survival prediction in lung adenocarcinoma: a multi-site, blinded validation study. Nat Med 14: 822-827, 2008.

65. Hammerman PS, Lawrence MS, Voet D, Jing R, Cibulskis K, Sivachenko A, Stojanov P, McKenna A, Lander ES, Gabriel S, et al; Cancer Genome Atlas Research Network: Comprehensive genomic characterization of squamous cell lung cancers. Nature 489: 519-525, 2012.

66. Yamauchi M, Yamaguchi R, Nakata A, Kohno T, Nagasaki M, Shimamura T, Imoto S, Saito A, Ueno K, Hatanaka Y, et al: Epidermal growth factor receptor tyrosine kinase defines critical prognostic genes of stage I lung adenocarcinoma. PLoS One 7: e43923, 2012.

67. Tomida S, Koshikawa K, Yatabe Y, Harano T, Ogura N, Mitsudomi T, Some M, Yanagisawa K, Takahashi T, Osada H and Takahashi T: Gene expression-based, individualized outcome prediction for surgically treated lung cancer patients. Oncogene 23: 5360-5370, 2004.

68. Bild AH, Yao G, Chang JT, Wang Q, Potti A, Chasse D, Joshi MB, Harpole D, Lancaster JM, Berchuck A, et al: Oncogenic pathway signatures in human cancers as a guide to targeted therapies. Nature 439: 353-357, 2006. 